\title{
Age and Growth of Nototodarus sloanii (Cephalopoda: Oegopsida) Based on Daily Increment Counts in Statoliths
}

\author{
Yuji Uozumi*1 and Hiroe Ohara*2 \\ (Received 21 August, 1992)
}

\begin{abstract}
Statoliths of Nototodarus sloanii collected around New Zealand were examined to determine age. By comparing the increase in number of increments in statoliths with the number of days elapsed between sampling dates, the periodicity of the increment formation was validated. Estimated hatching month ranged from January to December. This result suggests that spawning occurs throughout the year. The relationship between statolith radius and dorsal mantle length suggests daily increment width must reflect squid growth well. Back-calculation was applied to compensate for the short sampling period. The differences in size at age are significant between the seasonal groups. The winter group is larger than the summer one between about 100 and 230 days old. This difference became smaller and finally the summer group became larger than the winter one at around 250 days old and after. It is suggested that differences in growth between the groups are consistent with seasonal changes in water temperature.
\end{abstract}

The resources of arrow squids, comprised of Nototodarus sloanii and $N$. gouldi, rapidly became one of the most important fishery resources in the 1970 s, starting from an insignificant bycatch in New Zealand waters. The arrow squids are caught by both jig and trawl fisheries. A jig fishery developed by Japanese, Korean, and Taiwanese vessels around the mainland of New Zealand produced $30,000-60,000$ tonnes annually in the 1980s. A trawl fishery developed by Japanese, Russian, and Korean vessels produced $30,000-60,000$ tonnes in the $1980 \mathrm{~s}$, about half of which was taken around the Auckland Islands. The number of vessels in both fisheries, however, has decreased recently, mainly due to the shifting of their fishing grounds to the southern Atlantic Ocean to fish Illex argentinus

$N$. sloanii is widely distributed in waters down to about $500 \mathrm{~m}$ in depth around New Zealand except for the north and west coast of North Island." $N$. sloanii is caught by both jig and trawl fisheries mainly around the South Island and the Auckland Islands, and comprises a major part of the arrow squid catch, ${ }^{13}$ while $N$. gouldi is caught by the jig fishery off the west coast of the mainland.

The biology of $N$. sloanii was summarized by Kawakami, ${ }^{2}$ Mattlin et al., ${ }^{3)}$ and Smith et al. ${ }^{1}$.
These papers suggested a long but poorly defined spawning season and several seasonal and/or regional subpopulations. Growth was estimated from the progressive changes of modes in length composition, which were obtained from the waters around the Auckland Islands where a very clear succession of modes were observed. ${ }^{42}$

In this paper, the growth of $N$. sloanii was estimated from aging results using daily increments in the statoliths. Growth in the younger stages before recruitment into the fisheries was estimated by back-calculation.

\section{Materials and Methods}

\section{Samples and Data}

Most of the samples for aging were collected by Japanese squid jiggers and trawlers (Table 1). About $70 \%$ of them were collected in JanuaryApril 1991 on the Snares Shelf. Samples of juvenile squid were collected by a fine mesh midwater trawl (KMT midwater trawl net with $10 \mathrm{~mm}$ mesh cod-end) during a joint Japan-New Zealand squid survey by R/V Kaiyo Maru in July-September, 1985.3) Localities of samples are shown in Fig. 1.

*1 National Research Institute of Far Seas Fisheries, Shimizu 424, Japan (魚住雄二: 遠洋水産研究所).

*2 Tokai University, Shimizu 424, Japan (大原啓江: 東海大学海洋学部).

Present address: Nihonsouken Company, Hamamatsu 430, Japan (日本総碑). 
Table 1. Collection data for the statoliths used in this study

\begin{tabular}{|c|c|c|c|c|c|c|c|}
\hline \multicolumn{2}{|c|}{$\begin{array}{c}\text { Sampling } \\
\text { Date }\end{array}$} & \multicolumn{2}{|c|}{ Locality } & \multirow{2}{*}{$\frac{\begin{array}{c}\text { Depth } \\
(\mathrm{m})\end{array}}{140}$} & \multirow{2}{*}{$\frac{\begin{array}{c}\text { Type of } \\
\text { Gear }\end{array}}{M^{*}}$} & \multirow{2}{*}{$\frac{\begin{array}{c}\text { No. of } \\
\text { Specimens }\end{array}}{1}$} & \multirow{2}{*}{$\begin{array}{c}\text { Range of Size } \\
(\mathrm{mm} M L)\end{array}$} \\
\hline 85 & 84 & $43^{\circ} 18^{\prime} \mathrm{S}$ & $168^{\circ} 22^{\prime} \mathrm{E}$ & & & & \\
\hline 85 & 85 & $46^{\circ} 58^{\prime}$ & $168^{\circ} 49^{\prime}$ & 60 & M & 1 & $220-220$ \\
\hline 85 & 85 & $47^{\circ} 54^{\prime}$ & $168^{\circ} 19^{\prime}$ & 100 & $\mathrm{M}$ & 1 & $30-30$ \\
\hline 85 & 812 & $44^{\circ} 52^{\prime}$ & $171^{\circ} 33^{\prime}$ & 46 & $\mathrm{M}$ & 1 & 32- 32 \\
\hline 85 & 815 & $43^{\circ} 19^{\prime}$ & $175^{\circ} 15^{\prime}$ & 85 & M & 2 & $42-46$ \\
\hline 85 & 815 & $44^{\circ} 13^{\prime}$ & $175^{\circ} 53^{\prime}$ & 380 & M & 1 & $36-36$ \\
\hline 85 & 816 & $43^{\circ} 18^{\prime}$ & $173^{\circ} 23^{\prime}$ & 65 & $M$ & 22 & $15-65$ \\
\hline 85 & 919 & $43^{\circ} 19^{\prime}$ & $173^{\circ} 23^{\prime}$ & 65 & M & 3 & $48-60$ \\
\hline 90 & 117 & $47^{\circ} 51^{\prime}$ & $166^{\circ} 57^{\prime}$ & 149 & $\mathrm{~J}$ & 12 & $213-277$ \\
\hline 90 & 315 & $44^{\circ} 56^{\prime}$ & $171^{\circ} 48^{\prime}$ & 121 & $\mathrm{~J}$ & 4 & $140-269$ \\
\hline 90 & 325 & $48^{\circ} 30^{\prime}$ & $166^{\circ} 30^{\prime}$ & $?$ & B & 21 & $258-342$ \\
\hline 90 & 430 & $47^{\circ} 30^{\prime}$ & $169^{\circ} 35^{\prime}$ & $?$ & $\mathrm{~B}$ & 9 & $300-340$ \\
\hline 901 & 116 & $46^{\circ} 47^{\prime}$ & $166^{\circ} 03^{\prime}$ & 470 & B & 12 & $304-398$ \\
\hline 901 & 116 & $46^{\circ} 35^{\prime}$ & $166^{\circ} 08^{\prime}$ & 507 & $\mathrm{~B}$ & 14 & $268-352$ \\
\hline 91 & 110 & $41^{\circ} 29^{\prime}$ & $170^{\circ} 47^{\prime}$ & $?$ & $\mathfrak{J}$ & 1 & $230-230$ \\
\hline & 115 & $42^{\circ} 05^{\prime}$ & $170^{\circ} 40^{\prime}$ & $?$ & $\mathbf{J}$ & 2 & $216-232$ \\
\hline 91 & 115 & $41^{\circ} 16^{\prime}$ & $171^{\circ} 01^{\prime}$ & 189 & $\mathbf{J}$ & 7 & $172-256$ \\
\hline 91 & 117 & $45^{\circ} 08^{\prime}$ & $171^{\circ} 28^{\prime}$ & 132 & $\mathrm{~J}$ & 17 & $140-250$ \\
\hline & 117 & $45^{\circ} 08^{\prime}$ & $171^{\circ} 28^{\prime}$ & 122 & $\mathbf{J}$ & 10 & $120-158$ \\
\hline 91 & 118 & $46^{\circ} 31^{\prime}$ & $167^{\circ} 18^{\prime}$ & 115 & $\mathbf{J}$ & 30 & $98-202$ \\
\hline 91 & 123 & $48^{\circ} 50^{\prime}$ & $166^{\circ} 50^{\prime}$ & 185 & B & 30 & $126-168$ \\
\hline & 127 & $46^{\circ} 33^{\prime}$ & $167^{\circ} 18^{\prime}$ & 128 & $J$ & 41 & $142-280$ \\
\hline & 25 & $46^{\circ} 34^{\prime}$ & $167^{\circ} 14^{\prime}$ & $?$ & $J$ & 22 & $118-206$ \\
\hline & 210 & $46^{\circ} 29^{\prime}$ & $167^{\circ} 16^{\prime}$ & 124 & $\mathbf{J}$ & 31 & $160-264$ \\
\hline & 211 & $46^{\circ} 32^{\prime}$ & $167^{\circ} 18^{\prime}$ & $?$ & $J$ & 18 & $150-200$ \\
\hline & 215 & $46^{\circ} 32^{\prime}$ & $167^{\circ} 17^{\prime}$ & 117 & $J$ & 67 & $114-258$ \\
\hline & 215 & $48^{\circ} 38^{\prime}$ & $167^{\circ} 00^{\prime}$ & 133 & $J$ & 19 & $125-232$ \\
\hline & 215 & $48^{\circ} 33^{\prime}$ & $167^{\circ} 00^{\prime}$ & 137 & $\mathrm{~J}$ & 22 & $142-272$ \\
\hline & 215 & $48^{\circ} 33^{\prime}$ & $167^{\circ} 00^{\prime}$ & $?$ & $\mathbf{J}$ & 11 & $130-242$ \\
\hline & 215 & $46^{\circ} 33^{\prime}$ & $167^{\circ} 19^{\prime}$ & $?$ & $J$ & 22 & $152-222$ \\
\hline & 216 & $47^{\circ} 48^{\prime}$ & $167^{\circ} 09^{\prime}$ & 143 & $J$ & 29 & $142-218$ \\
\hline 91 & 221 & $48^{\circ} 50^{\prime}$ & $167^{\circ} 03^{\prime}$ & 180 & B & 22 & $204-242$ \\
\hline 91 & 31 & $48^{\circ} 23^{\prime}$ & $168^{\circ} 06^{\prime}$ & $?$ & B & 31 & $208-272$ \\
\hline \multirow[t]{2}{*}{91} & 418 & $47^{\circ} 33^{\prime}$ & $169^{\circ} 07^{\prime}$ & 532 & B & 54 & $108-342$ \\
\hline & & & & & Total & 601 & $15-398$ \\
\hline
\end{tabular}

\section{Statolith Processing and Count of Increments}

After the measurement of dorsal mantle length (ML), the statoliths were removed and stored in liquid paraffin. Aging was carried out using these statolith samples. Processing and counting procedures were according to Uozumi and Shiba. ${ }^{\text {b) }}$ Each statolith was mounted individually with the anterior concave side down on a glass slide using a single drop of super glue (cyanoacrylate adhesive). The statoliths were then ground by hand on fine waterproof sandpaper and finally polished using alumina polish. A microscope equipped with a color TV camera system was used during the grinding procedure and for viewing the incre- ments in the statoliths. Counting was carried out on a 15 -inch color TV monitor at 920x magnification.

The increments were most discernible in the dorsal dome, especially along the wing attachment area (Fig. 2). Increments were usually counted in this area from the core to the edge region. Since the increments in the terminalmost portion of the statoliths could not be counted in most samples, the number of increments in this area was derived by extrapolation based on those counted in the nearest area where counting was possible. The proportion of the estimated number of increments to the total was about $5 \%$, 


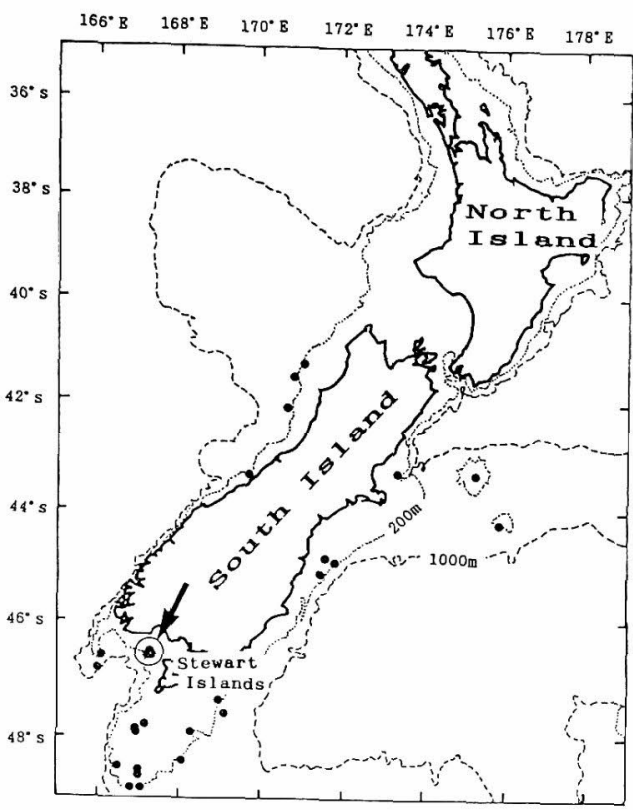

Fig. 1. The localities of samples. Solid circles show the sampling sites.

The arrow and open circle show the sampling area which was used for the validation study.

regardless of the size of statolith.

\section{Back-calculation}

The number of juvenile samples was insufficient to derive the appropriate growth curve in this study. Therefore, a back-calculation method which estimates the length at the time when the rings were formed was applied to estimate length at younger ages. ${ }^{7)}$ This method has been used commonly in studies on the growth of fishes.?

This method needs the relationship between statolith radius and mantle length, and each monthly radius. Measurements of statolith radius and monthly radii (radius of each 30 increments) were carried out on a TV monitor using a digital map meter (COMCURVE-5, Koizumi Sokki Mfg Co., Ltd) at 920x magnification. The statolith radius and monthly radii were measured from core to tip of the dorsal dome along the curved axis shown in Fig. 3. Measurement of the statolith radius was carried out in almost all of the observed specimens which were not broken in the measurement area, while the measurement of monthly radii was carried out in 20 specimens hatched in the same month.

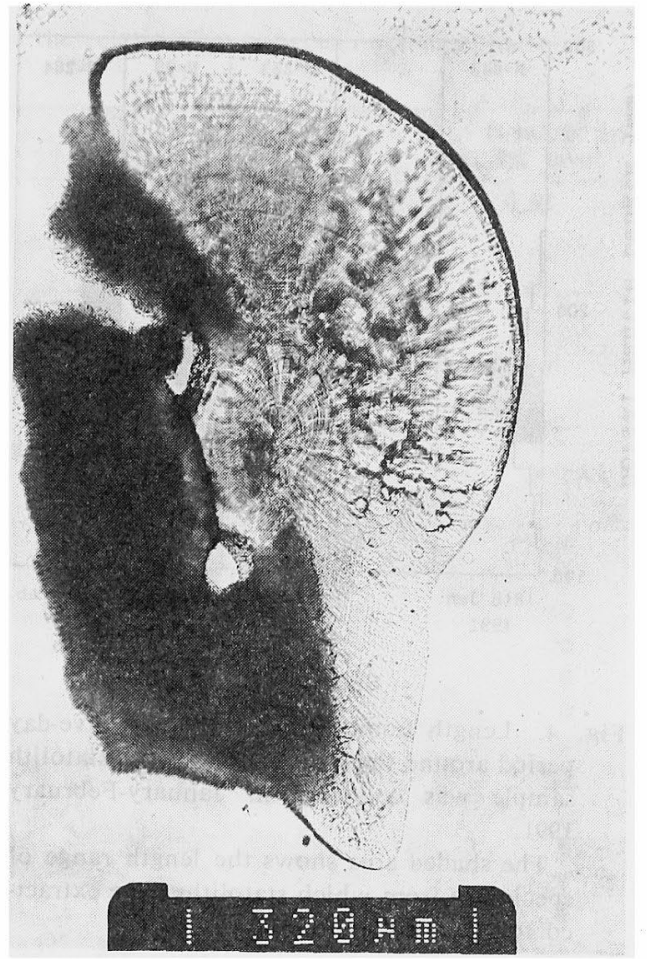

Fig. 2. Photo micrograph of the posterior convex view of a ground statolith, from Nototodarus sloanii with a dorsal mantle length of $200 \mathrm{~mm}$.

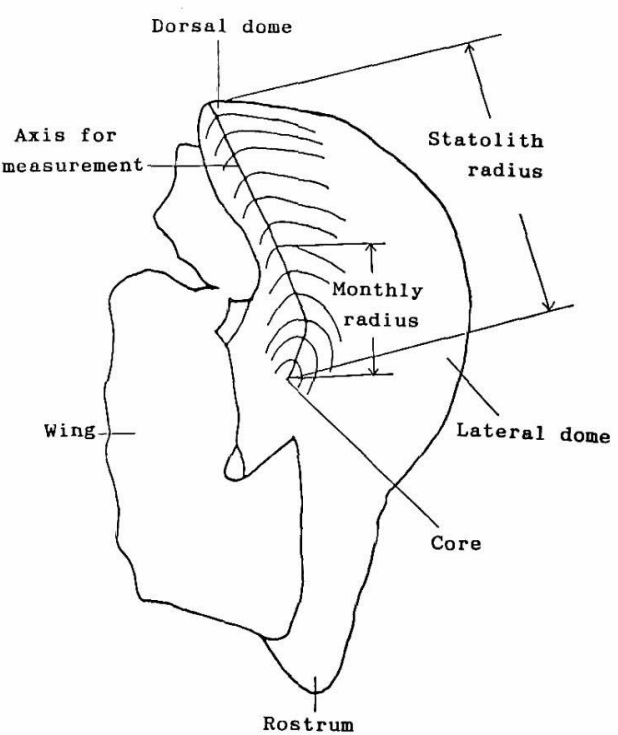

Fig. 3. Schematic view of statolith showing the axis for the measurements. 


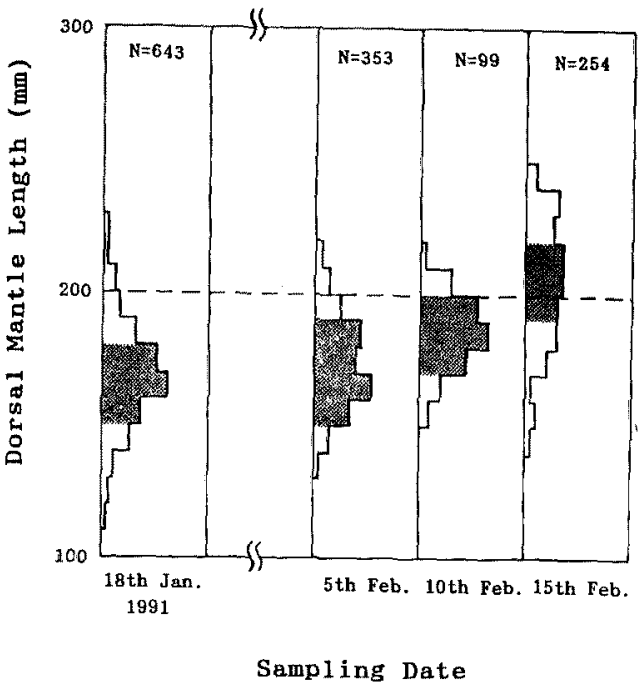

Fig. 4. Length compositions for each five-day period around the date on which each statolith sample was collected in January-February 1991 .

The shaded area shows the length range of specimens from which statoliths were extracted for the validation study.

\section{Validation of Daily Increment Formation}

For validation of the periodicity of increment formation, no direct method such as the use of a chemical marker ${ }^{8-10}$ ' was carried out in this study. So another type of validation was tried which involved comparing the number of increments in the statoliths with the date of capture. ${ }^{0}$ )

The data and specimens used in the validation were collected from a very restricted area of a 8 square miles (shown by the arrow in Fig. 1), during 29 days from 18th January to 15th February 1991. Length composition for each five-day period around the date on which each statolith sample was collected are shown in Fig. 4. Statoliths were selected from the modal region of length compositions (shaded area of Fig. 4), regardless of sex.

\section{Statistical Analyses}

A predictive regression model was applied to the analysis of the relationship between the number of increments and the sampling date. A cubic curve was fitted to the relationship between statolith radius and mantle length. A logistic curve was fitted to express the growth of squid based on Marquardt's method. ${ }^{113}$

Akaike's Information Criterion (AIC) was util- ized as a criterion in the selection of models for logistic growth and the relationships between statolith radius and mantle length. It is known that the model with the lowest $A I C$ gives the best selection. ${ }^{28}$ The two models, sex-separated and sex-combined ones, were constructed for the logistic growth and relationship between statolith radius and mantle length, respectively. Based on the $A I C$ values, the optimal model was selected, because the parameters of the logistic curves were estimated by a non-linear method and it is difficult to apply conventional statistical methods such as covariance analysis.

The $A I C$ for each model is expressed in equation as follows:

For sex-combined model,

$$
A I C=N \cdot \ln (2 \pi \cdot S S / N)+N+2 \cdot N P
$$

where $N$ : number of specimens In: natural logarithm $S S$ : sum of squares NP: number of parameters

For sex-separated model,

$$
\begin{gathered}
A I C=N_{1} \cdot \ln \left(2 \pi \cdot S S_{1} / N_{1}\right)+N_{1}+2 \cdot N P+N_{2} . \\
\quad \ln \left(2 \pi \cdot S S_{2} / N_{2}\right)+N_{2}+2 \cdot N P
\end{gathered}
$$

where subscripts refer to variables for male and female, respectively.

\section{Results}

\section{Validation of Daily Increment Formation}

In sequential length composition, a gradual progression was observed in the modes from

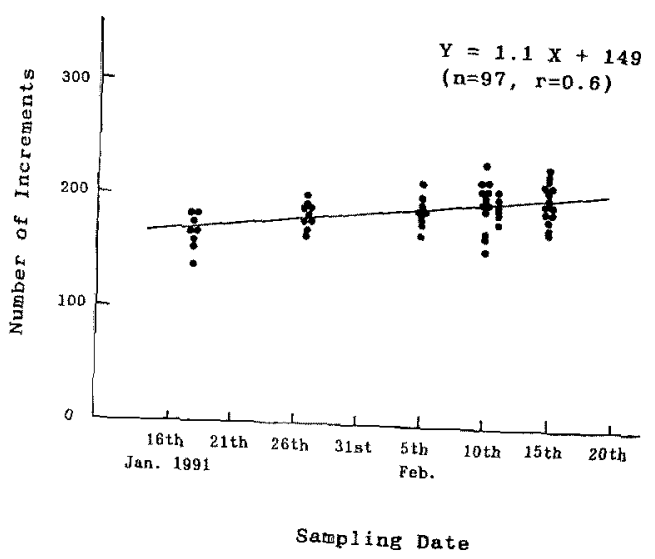

Fig. 5. Relationship between the number of increments in the statoliths and the date on which the samples were collected in JanuaryFebruary 1991. 
Table 2. The result of analysis of variance for the relationship between number of increments and sampling date

\begin{tabular}{lcrrrr}
\hline \hline Factor & SS & DF & MS & F-value & $\begin{array}{c}\text { F-value } \\
\text { at level }\end{array}$ \\
\hline Regression & 10384.20 & 1 & 10384.20 & 55.5 & 6.91 \\
Error & 17784.50 & 95 & 187.21 & & \\
Total & 28168.70 & 96 & & & \\
\hline
\end{tabular}

Table 3. The number of specimens observed with respect to the hatching month and the month in which the sampling was done

\begin{tabular}{|c|c|c|c|c|c|c|c|c|c|c|c|c|c|}
\hline \multirow{2}{*}{$\begin{array}{l}\text { Month } \\
\text { sampled }\end{array}$} & \multicolumn{12}{|c|}{ Hatching month } & \multirow{2}{*}{ TOTAL } \\
\hline & JAN & FEB & MAR & APR & MAY & JUN & JUL & AUG & SEP & OCT & NOV & $\mathrm{DEC}$ & \\
\hline JAN & & & & & 9 & 18 & 44 & 64 & 1 & & & & 136 \\
\hline FEB & & & & & & 3 & 70 & 163 & 5 & & & & 241 \\
\hline MAR & & & & & 1 & 16 & 19 & 13 & 1 & & & & 50 \\
\hline APR & & & & & & 1 & 4 & 20 & 24 & 7 & & & 56 \\
\hline MAY & & & & & & & & & & & & & 0 \\
\hline JUN & & & & & & & & & & & & & 0 \\
\hline JUL & & & & & & & & & & & & & 0 \\
\hline AUG & 1 & & & 20 & 11 & & & & & & & 1 & 33 \\
\hline SEP & & & & & 1 & & & & & & & & 1 \\
\hline OCT & & & & & & & & & & & & & 0 \\
\hline NOV & 7 & 7 & 8 & & & & & & & & & 2 & 24 \\
\hline DEC & & & & & & & & & & & & & 0 \\
\hline Total & 8 & 7 & 8 & 20 & 22 & 38 & 137 & 260 & 31 & 7 & 0 & 3 & 541 \\
\hline
\end{tabular}

$160 \mathrm{~mm} M L$ on 18th January to $210 \mathrm{~mm} M L$ on 15th February (Fig. 4). This progression suggested that all the samples were derived from the same cohort.

There was a linear relationship between the number of increments for these specimens and the sampling date (Fig. 5). The equation for the regression of the number of increments on sampling date was;

$$
Y=1.1 X+149 \quad(r=0.6, n=97)
$$

where $Y=$ the number of increments observed in the statoliths,

$X=$ catch date expressed as the number of days since 1st Jaunary 1989,

$r=$ correlation coefficient, and

$n=$ number of individuals observed.

Analysis of variance showed that this regression was significant at the $1 \%$ level (Table 2 ) and the $95 \%$ confidence interval of the slope was 0.80-1.4. The estimated value of the slope was very close to 1 , which means that the formation of each increment takes about one day.

Another problem related to the interpretation of the number of increments is determining the age (or stage) of initiation of increment formation.
It is impossible to resolve this problem until statoliths from reared larval squid can be obtained. Therefore, it was assumed that increment formation begins at the time of hatching. Under this assumption, the number of increments signifies age in days after hatching.

\section{Hatching Month and Growth of Overall Samples}

In total, 541 specimens were aged successfully. Following the validation, the day of hatching of each specimen can be estimated from age in days (number of increments) and the date of the sample. These results were compiled into hatching month composition (Table 3). Hatching month ranged from January to December, except for November. The wide range of hatching month distribution suggested that spawning occurs throughout the year.

The relationship between age in days and $M L$ is shown in Fig. 6 according to sex. The ages of the specimens ranged from 88 to 318 days old. Figure 6 suggests that there might be one inflection point in the growth curve. The logistic curves were estimated for the two models, i.e. sex-separated and sex-combined models, excluding the unsexed specimens. The $A I C$ calculated for each 


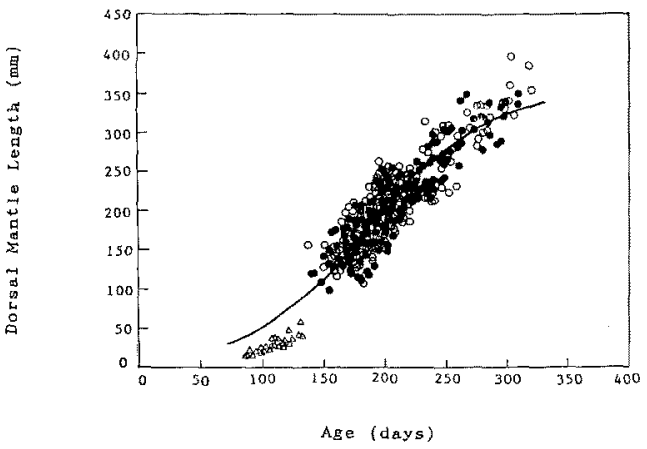

Fig. 6. Relationship between age and dorsal mantle length for all specimens aged in the study according to sex.

Open and solid circles show females and males, respectively, while triangles show unsexed specimens. Solid curve shows the final growth curve for the sex-combined model.

Table 4. $A I C$ values for the sex-separated and sex-combined models in logistic growth equation

\begin{tabular}{llllc}
\hline & & Number & $\begin{array}{c}\text { Sum of } \\
\text { square }\end{array}$ & AIC \\
\hline Sex-separated & & & & $4,725.5$ \\
& Male & 257 & 143,114 & $(2,362.0)$ \\
Female & 252 & 169,263 & $(2,363.5)$ \\
Sex-combined & 509 & 313,618 & $4,721.8$ \\
\hline
\end{tabular}

model suggested that the sex-combined model was the optimal one for the present study (Table 4). The final equation was estimated using the sexcombined data including unsexed specimens. The resulting equation is as follows:

$$
M L=355.7 /\left(1+\mathrm{e}^{-0.021(\ell-180.5)}\right)
$$

where $M L=$ dorsal mantle length ( $\mathrm{mm}$ )

$$
t=\text { age in days. }
$$

The optimal growth curve is shown in Fig. 6 . It is clear that the growth curve expressed growth between 150 and 300 days old very well, but there are some discrepancies between observed and estimated sizes at ages younger than 150 days old.

There is a possibility that this overestimation of growth in younger ages may be caused by the insufficient number of younger squid samples and seasonal variability in growth, because the hatching month is widely distributed throughout the year (Table 3 ).

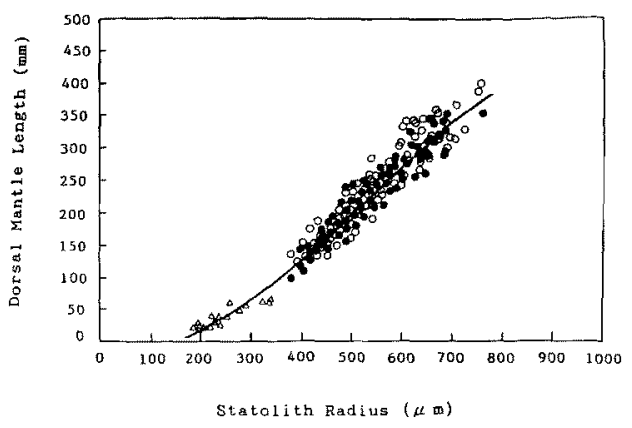

Fig. 7. Relationship between dorsal mantle length and statolith radius.

Open and solid circles show females and males, respectively, while triangles show unsexed specimens. Solid curve shows the final cubic curve for the sex-combined model.

Table 5. AIC values for the sex-separated and sex-combined models in relationship between

\begin{tabular}{|c|c|c|c|c|}
\hline \multicolumn{3}{|c|}{ Number } & \multirow[t]{2}{*}{$\begin{array}{l}\text { Sum of } \\
\text { square }\end{array}$} & \multirow{2}{*}{$\frac{\mathrm{AIC}}{5,052.6}$} \\
\hline Sex-separated & & & & \\
\hline & Male & 231 & 598,721 & $(2,481.1)$ \\
\hline & Female & 236 & 715,081 & $(2,571.5)$ \\
\hline Sex-combined & & 467 & $1,313,800$ & $5,044.0$ \\
\hline
\end{tabular}
statolith radius and mantle length

\section{Back-calculation}

To analyze the growth in the younger stages, back-calculation was applied. The relationship between statolith radius and mantle length is shown in Fig. 7 according to sex. Cubical parabolas were estimated for the two models, i.e. sex-separatedand sex-combined models, excluding the unsexed specimens. The $A I C$ calculated for each model suggested that the sex-combined model was the optimal one for the present study (Table 5). The final equation was estimated using the sexcombined data including unsexed specimens. The resulting equation is as follows:

$$
\begin{array}{r}
M L=-0.11-0.22 S R+0.018 S R^{2}-1.1 \cdot 10^{-8} S R^{3} \\
(n=501, R=0.97)
\end{array}
$$

where $M L=$ dorsal mantle length in $\mathrm{mm}$,

$S R=$ statolith radius in $\mu m$,

$n=$ number of specimens, and

$R=$ multiple correlation coefficient.

This equation was used for back-calculation of $M L$ at the time when each monthly radius was formed. Because this equation expressed the relationship between 200 and $780 \mu \mathrm{m}$ in statolith 
Table 6. Back-calculated mantle length at each 30 days old by hatching months

\begin{tabular}{|c|c|c|c|c|c|c|c|c|}
\hline \multirow{2}{*}{ Hatching month } & \multicolumn{7}{|c|}{$\begin{array}{c}\text { Back-calculated mean mantle length (mm) } \\
\text { at each age (days) }\end{array}$} & \multirow{2}{*}{$\begin{array}{c}\text { Number } \\
\text { of } \\
\text { specimens }\end{array}$} \\
\hline & 90 & 120 & 150 & 180 & 210 & 240 & 270 & \\
\hline December/January & 12.0 & 37.3 & 74.3 & 117.0 & 164.3 & 214.5 & 268.3 & 7 \\
\hline February/March & 14.0 & 45.3 & 88.9 & 135.5 & 186.0 & 228.7 & - & 10 \\
\hline April & - & - & - & - & - & - & - & - \\
\hline May & 14.1 & 43.1 & 81.4 & 126.9 & 180.0 & - & - & 8 \\
\hline June & 14.5 & 46.8 & 88.8 & 138.3 & - & - & - & 20 \\
\hline July & 21.5 & 60.2 & 107.7 & - & - & - & - & 20 \\
\hline August & 16.6 & 54.8 & 107.7 & - & - & - & - & 20 \\
\hline September & 20.1 & 56.1 & 104.4 & 140.0 & - & - & - & 18 \\
\hline October & 18.0 & 52.8 & 96.4 & 151.8 & - & - & - & 5 \\
\hline November & - & - & - & - & - & - & - & - \\
\hline
\end{tabular}

radius, application of back-calculation was limited in this range. Thus, the lower limit roughly corresponded to 90 days of age.

\section{Growth of Summer and Winter Hatching Groups}

The $M L$ at each monthly radius was estimated starting from 90 days for each hatching month group, though the sample numbers were variable from group to group (Table 6). The samples of December/January and February/March hatching month groups were pooled due to the small sample number and the mean $M L$ at each month radius was calculated for each hatching month group, while the aging results were also pooled for each hatching month group and the mean $M L$ at every ten-day interval was calculated.

The hatching month groups were grouped into two seasonal groups arbitrarily, namely austral summer (December/March) and austral winter (June/September) hatching groups, because the number of samples in each hatching month group was insufficient for the estimation of the growth curve for each one. The relationship between age and $M L$ is shown in Fig. 8. This figure indicates that the size at age estimated by the two methods, counting increments and back-calculation are consistent with each other in each seasonal group. The logistic curves were fitted to each seasonal group (Fig. 8). The estimated equations are as follows:

Austral summer group:

$$
M L=393.8 /\left(1+\mathrm{e}^{-0.023(t-212.3)}\right)
$$

Austral winter group:

$$
M L=336.6 /\left(1+\mathrm{e}^{-0.024(t-170.5)}\right)
$$

where $M L=$ dorsal mantle length $(\mathrm{mm})$ $t=$ age in days.

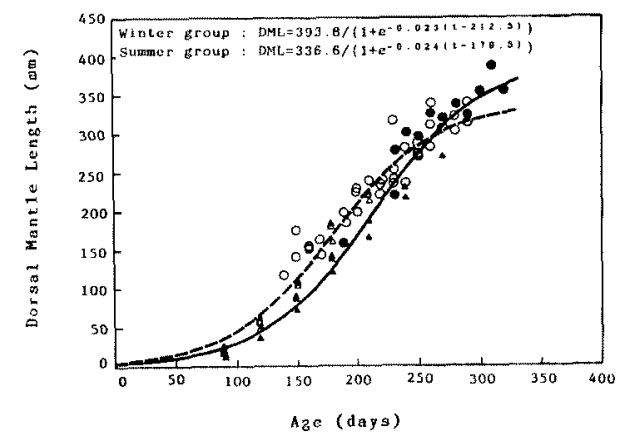

Fig. 8. Relationships between age and dorsal mantle length for summer and winter groups. Solid triangle and circle, summer group; open triangle and circle, winter group. Triangles show the means by back-calculation and circles show the means by counting increments. Solid and broken curves show the estimated logistic curves for summer and winter groups, respectively.

The growth equations express the growths of both seasonal groups very well. They are more appropriate than the growth equation estimated for all samples combined (Figs. 6 and 8 ).

The growth of both seasonal groups gradually became faster at younger ages until about 150 days, and the rate of growth was the fastest at around 180 days, reaching about $40-60 \mathrm{~mm}$ per month, and then becomes slower at older ages. The differences in size at age are significant between the groups. The winter group is larger than the summer group between about 100 and 230 days old, especially around 180 days old and the maximum difference was about $40 \mathrm{~mm}$. This difference became smaller at older ages, until finally the summer group became larger than the winter 
one at around 250 days old and thereafter.

\section{Discussion}

By comparing the increase in the number of increments in statoliths with the number of days elapsed between sampling dates, the periodicity of increment formation was validated under the assumption that the samples were collected from the same cohort. The results indicate that the increments observed in this study are formed daily. Daily formation of the increments has been directly validated in other ommastrephid spocies (Illex illecebrosus and Todarodes pacificus) with a chemical marker. ${ }^{8,10}$ It is desirable that a direct method of validation should be applied to aging methods for $N$. sloanit.

The period between formation of statocysts and hatching in Todarodes pacificus is short (about one day at $14-20^{\circ} \mathrm{C}$ ). ${ }^{13}$ ) Immediate post-hatching paralarvae of Illex illecebrosus from the laboratory had one or no increments in their statoliths. ${ }^{14}$ ) These results suggested that the number of increments represents the number of days after hatching in ommastrephid squids. Therefore, there is a high possibility that the number of increments signifies age in days after hatching in N. sloanii.

The life span of $N$. sloanii has appeared to be about one year, based on length composition data. ${ }^{2,3)}$ Length composition data showed that the maximum length reaches nearly $400 \mathrm{~mm}$ $M L .^{2-4)}$ In this study the age of the oldest specimen was 318 days and its length was $386 \mathrm{~mm} M L$. The age of the specimens which attained more than $350 \mathrm{~mm} M L$ ranged from 260 to 318 days. The results indicate that the life span of this species may be about one year, though the number of larger specimens was not sufficient to estimate the exact life span.

Back-calculation was applied to compensate for the short sampling period (mainly from January to April) compared to the life span. Campana and Neilson ${ }^{15)}$ suggested the potential value of back-calculation using daily increments. The growth patterns of statolith length and mantle length were described by a smooth-monotonic curve in N. sloanii. This relationship suggested that daily increment width must reflect squid growth well. Applying back-calculation, it is easy to estimate the growth of smaller squid before recruitment to the fishery. There was little discrepancy between the results of back calculation and actual aging (Fig. 8) and these results also indicated differences in the growth of younger stages between seasonal groups.

In the present study the logistic curve was applied to the growth of $N$. sloanit, because this model is the most popular one for experssing growth which has one inflection point. The logistic curve expresses the growth of each seasonal group very well through the range of ages observed. Figures 6 and 8 suggested that growth might not be asymptotic, though there was an insufficient number of samples larger than $300 \mathrm{~mm} M L$. This result suggested that parameter $L_{\infty}$ of the logistic model has little biological meaning.

The present results show that there is no signifcant difference in growth between the sexes. Uozumi and Kuroiwa ${ }^{4}$ indicated that there was no significant difference in modal lengths between the sexes for squid smaller than about $20 \mathrm{~cm} M L$ but that the modal size of female squid is $2-3 \mathrm{~cm}$ larger than that of males of sizes larger than $30 \mathrm{~cm}$ $M L$. They suggested that there is a difference in growth between the sexes, especially in older ages based on the difference in modal lengths. In the present study, most of the specimens were smaller than $25 \mathrm{~cm} M L$, and there were not enough specimens of larger sizes than about $25 \mathrm{~cm} M L$ to investigate the difference in growth between the sexes. Therefore, it is necessary to collect a sufficient number of samples for older squid and to investigate the difference in size at age at older ages between the sexes, before a final conclusion on the difference in growth between the sexes can be reached.

The speed of growth in length is a maximum of around 180 days old in the whole life span of the squid, and reaches $40-60 \mathrm{~mm} /$ month. This suggests that only one month delay in birth would results in well-separated modes in length distribution. It is usually observed that there are some well-separated modes in length composition. ${ }^{3,16,17)}$ It is commonly understood that different modes indicate different seasonal cohorts. But judging from the fast-growing characteristics of the squid shown in the present study, there is a possibility that the-well separated modes may be due to only one or two months' delay in hatching.

The growth of the winter group, around 180 days old, is faster than that of the summer group. The winter group spends a period of around 180 days in the summer season, while the summer group spends this period in the winter season. At ages of more than about 250 days, the growth of 
the summer group becomes faster than that of the winter one. Water temperature in the area sampled show clear seasonal changes. A high temperature (about $15^{\circ} \mathrm{C}$ ) is observed in the austral summer from December to March, while a low temperature (around $10^{\circ} \mathrm{C}$ ) is observed in the austral winter from July to August. ${ }^{18}$ It is clear that the growth rate is higher in summer than in winter at the same age. Differences in growth between the seasonal groups are consistent with the seasonal changes in water temperature, though there is no direct evidence for a relationship between temperature and growth.

The length-based method has usually been applied to the study of squid growth, ${ }^{4,102}$ on the assumption that the individuals which comprised the corresponding mode observed in the time series should belong to the same cohort. However, it is difficult to validate this assumption without aging. Uozumi and Shiba ${ }^{\text {b) }}$ pointed out that this assumption may not hold in species which migrate with growth. Furthermore, there are difficulties in following the corresponding modes in a time series, especially for species such as $N$. sloanii which have a wide spawning season, several modes in length composition, and a high growth rate. The aging technique using statoliths makes it possible to validate the assumption of the length-based method and to easily follow the same cohort in a time series precisely even for species which have a complex stock structure.

\section{Acknowledgments}

We extend special thanks Dr.P. Rodhouse (British Antarctic Survey, United Kingdom), Drs. H. Hatanaka and S. Kawahara (National Research Institute of Far Seas Fisheries, Japan), Prof. S. Ueyanagi (Tokai University) and Dr. T. Kubodera (National Science Museum, Tokyo) for their critical reading of the manuscript and helpful comments. We wish to express our thanks to Dr. K. Hiramatsu (National Research Institute of Far Seas Fisheries) for his valuable advice on the statistical treatment of the data.

\section{References}

1) P. J. Smith, R. H. Mattlin, M. A. Roeleveld, and T. Okutani: Arrow squids of the genus Nototodarus in New Zealand waters: systematics, biology, and fisheries. N. Z. Jour, Mar. Freshw. Res, 21, 315-326 (1987).

2) T. Kawakami: The fishery biological study on a squid Nototodarus sloani (Gray) in the New Zealand waters. Bull. Tokai Reg. Fish. Res. Lab. 85, 31-104 (1976) (in Japanese with English abstract)

3) R. H. Mattlin, R. E. Scheibling, and E. C. Forch: Distribution, abundance and size structure of arrow squid (Nototodarus sp.) off New Zealand. NAFO Studies, 9, 39-45 (1985).

4) Y. Uozumi and M. Kuroiwa: The growth of Nototodarus sloanil based on size frequency data. Cont. Fish. Res. Japan Sea Block, 17, 138-143 (1990) (in Japanese).

5) Y. Uozumi, E. C. Forch, and T. Okazaki: Distribution and morphological characters of immuature Martialia hyadesi (Cephalopoda: Oegopsida) in New Zealand waters. $N, Z$. Jour. Mar. Freshw. Res., 25, 275-282 (1991).

6) Y. Uozumi and C. Shiba: Growth and age composition of Illex argentinus (Cephalopoda: Oegopsida) based on daily increments counts in statolith, in "Recent Advances in Cephalopod Fisheries Biology" (ed. by T. Okutani, R. K. O'Dor, and T. Kubodera), Tokai University Press, Tokyo, 1993, pp, 587-605.

7) K. D. Carlander: A history of scale age and growth studies of North American freshwater fish, in "Age and Growth of Fish" (ed. by R. C. Summerfelt and G. E. Hail), lowa State University Press, 1987, pp. 3-13.

8) E. G. Dawe, R, K. O'Dor, P. H. Odense, and G. V. Hurley: Validation and application of an ageing technique for shortfinned squid (Illex illecebrosus). J. Northw. All. Fish. Sci., 6, 107-116 (1985).

9) M. Lipinski: Methods for the validation of squid age from statoliths. J. Mar. Biol. Ass. U.K., 66, 505-526 (1986),

10) Y. Nakamura and $Y$. Sakurai: Validation of daily growth increments in statoliths of Japanese common squid, Todarodes pacificus. Nippon Suisan Gakkaishi, 57, 2007-2011 (1991).

11) T. Akamine: Expansion of growth curves using a periodic function and BASIC program by Marquardt's method. Bull. Jap, Sea. Reg. Fish. Res. Lab., 36, 77-107 (1986).

12) Y. Sakamoto, M. Ishiguro and G. Katagawa: Akaike Information Criterion Statistics. KTK Scientific Publishers, Tokyo, 1986, pp. 107-146.

13) M. Hamabe: Embryological studies on the common squid, Ommastrephes sloani pacificus Steenstrup, in the southwestern waters of the Sea of Japan. Bull. Jap. Sea. Reg. Fish. Lab., 10, 1-45 (1962) (in Japanese with English abstract).

14) N. Balch, A. Sirois, and G. Hurley: Growth increments in statoliths from paralarvae of the ommastrephid squid lllex (Cephalopoda: Teuthoidea). Malacologia, 29, 103-112 (1988).

15) S. E. Campana and J.D. Neilson: Microstructure of fish otoliths. Can. J. Fish. Aquat. Sci., 42, 1014-1032 (1985).

16) H. Hatanaka, Y. Uozumi, J. Fukui, M. Aizawa, and R. J. Hurst: Japan-New Zealand trawl survey off southern New Zealand, October-November 1983. N. Z. Fish. Tech. Rep., 9, 1-52 (1989).

17) H. Hatanaka, Y. Uozumi, J. Fukui, M. Aizawa, and M. E. Livingston: Trawl survey of hoki and other slope fish on the Chatham Rise, New Zealand, Novermber-December 1983. N. Z. Fish. Tech. Rep., 17, 1--32 (1989).

18) M. Greig, N. M. Ridgway and B. S. Shakespeare: Sea surface temperature variation at coastal sites around New Zealand. N, Z. Jour. Mar. Freshw. Res., 22, 391-400.

19) H. Hatanaka: Growth and life span of short-finned squid Illex argentinus in the waters off Argentina. Nippon Suisan Gakkaishi, 52, 11-17 (1986). 